\title{
The Stromal Cell-derived Factor-1/CXCL12 3'A-gene Polymorphism is Related to the Increased Risk of Coronary Artery Disease: A Systematic Review and Meta-analysis
}

I Putu Yuda Prabawa ${ }^{1,2}$, Anak Agung Wiradewi Lestari ${ }^{2 *}$, I Made Muliarta ${ }^{3}$, Putu Eka Mardhika ${ }^{4}$, Gusti Ayu Riska Pertiwi ${ }^{5}$, Agha Bhargah ${ }^{5,6}$, Ida Bagus Amertha Putra Manuaba ${ }^{7}$, I Made Junior Rina Artha ${ }^{5}$, I Ketut Rina ${ }^{8}$, Starry Homenta Rampengan ${ }^{9}$

${ }^{1}$ Master Program in Biomedicine, Faculty of Medicine, Universitas Udayana, Bali, Indonesia; ${ }^{2}$ Department of Clinical Pathology, Faculty of Medicine, Universitas Udayana, Sanglah General Hospital, Bali, Indonesia; ${ }^{3}$ Department of Physiology, Faculty of Medicine, Universitas Udayana, Bali, Indonesia; ${ }^{4}$ Department of Neurosurgery, Faculty of Medicine, Universitas Udayana, Sanglah General Hospital, Bali, Indonesia; ${ }^{5}$ Department of Cardiovascular, Faculty of Medicine, Universitas Udayana, Sanglah General Hospital, Bali, Indonesia; ${ }^{6}$ General Practitioner, Faculty of Medicine, Udayana University, Bali, Indonesia; ${ }^{7}$ International Ph.D. Program in Medicine, College of Medicine, Taipei Medical University, Taipei, Taiwan; ${ }^{8}$ Department of Cardiology and Vascular Medicine, Puri Raharja General Hospital, Bali, Indonesia; ${ }^{9}$ Department of Cardiology and Vascular Medicine, Universitas Sam Ratulangi, Prof. Dr. R.D Kandou General Hospital, Manado, Indonesia

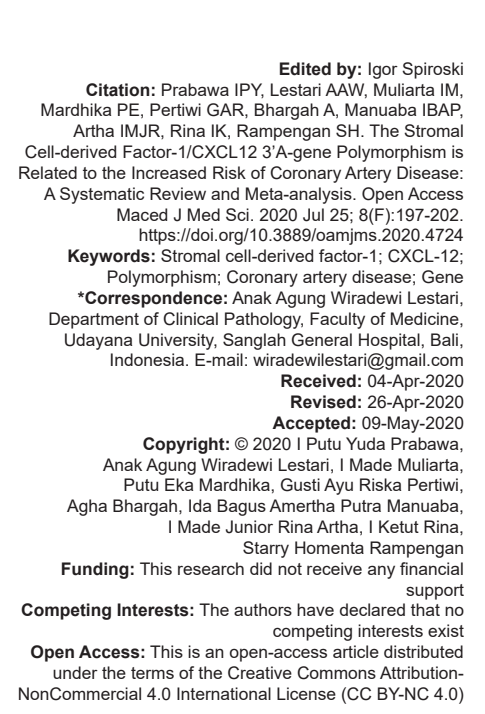

Abstract

BACKGROUND: Single-nucleotide polymorphism in the stromal cell-derived factor-1 (SDF-1)/CXCL12 gene had been associated with an increased risk of coronary artery disease (CAD). However, several published studies have shown inconsistent results.

AIM: A meta-analysis was assessed to evaluate the association between SDF-1 3'A-gene polymorphism and CAD in the literature.

METHODS: A systematic review was conducted in accordance with PRISMA guidelines and adhering to the Cochrane Handbook for Systematic Reviews. The literature search strategy was carried out on April 3, 2019, from PubMed, EBSCO, Google Scholar, and DOAJ during 2013-2018 period using various keywords related to SDF-1, CXCL12, polymorphism, and CAD. Original data from the group, case-control study, English full-text, and DNA polymorphism assessment using polymerase chain reaction were enrolled. Gene polymorphism in A-base nucleotide among patients with CAD and healthy subjects were evaluated. All data were analyzed using Review Manager 5.3 (Cochrane, Denmark) for meta-analysis.

RESULTS: Five eligible studies extracted for data analysis (2013-2018) based on the assessment of 2-independent reviewers. Several studies have been excluded due to irrelevant criteria evaluated. A significant result was found between SDF-1 3'A gene polymorphism with the increased risk of CAD in the overall effect evaluation using a fixedeffects model (odds ratio [OR]: 2.02; 95\% confidence interval 1.54-2.65; I2: 34\%; $p<0.001$ ) on the forest plot.

CONCLUSION: Our meta-analysis suggests that gene polymorphism in A-base nucleotide of SDF-1/CXCL-12 was associated with the susceptibility of CAD. However, a bigger-scale and well-design of case-control study should be conducted to clarify these conclusions.

\section{Introduction}

Coronary artery disease $(C A D)$ is one of cardiovascular disease which has been well known as the leading cause of death in both developed and developing countries [1]. CAD is an atherosclerotic disease that occurs in the coronary artery, which is manifested by stable angina, unstable angina, myocardial infarction, or sudden cardiac death [2]. The characteristic of pathological changes in atherosclerosis results from the endothelial injury or functional disorder, which is triggered by the abnormal accumulation of lipoproteins in the intima, as well as chronic inflammation [3]. As chronic inflammation, the immune system also plays critical roles in the initiation and propagation of atherosclerosis [4]. Several studies have shown that the dysregulation of immune cells and chemokines results in the progression of atherosclerosis, plaque instability, and the subsequent onset of acute coronary syndrome (ACS, including unstable angina pectoris and acute myocardial infarction [MI]) [4], [5].

Atherosclerosis is manifested as foam cell accumulation beneath the endothelial cell as well as smooth muscle recruitment, which leads to thrombus formation [5]. Several chemokines have been known to promote this process; one of them is stromal cell-derived factor-1(SDF-1). SDF-1, also called as chemokine (C-X-C motif) ligand 12 (CXCL12), is one of the family members of CXC chemokine located on chromosome 10q11.21 and mostly known for its pivotal role in the smooth muscle 
progenitor cells (SPCs) accumulation [6], [7]. MAPK and $\mathrm{PI} 3 \mathrm{~K}$ pathway also trigger the macrophage migration, particularly in the foam cell formation by binding of SDF-1 to CXCR4, a G-protein coupled receptor [8]. In addition, the SDF-1 expression also acts as a chemoattractant to recruit immune leukocyte cells, such as lymphocytes and monocytes, and, in turn, regulates the pro-inflammation cascade pathway which is responsible for plaque rupture and the occurrence of CAD such as MI [9].

Since lymphocytes and monocytes are prominent in the progression of atherosclerosis, it has been suggested that the disruption of SDF-1 function plays a critical role in the pathogenesis of CAD as well as could be used as a prognostic biomarker [10]. The disruption of SDF-1 has been proposed associated with the genetic variability caused by single nucleotide polymorphism (SNP) which leads to its overexpression in atheroma plaque [11]. There is strong evidence that SNP loci in the SDF-1 genes are associated with the risk of CAD due to a transition of G-to-A base ( $\mathrm{G}>\mathrm{A}$ ) at position 801 in the 3'untranslated region (UTR) [11], [12]. However, a different race between Asian and Caucasian as well as the time of studies differ from the previous studies [11], [13]. Therefore, a systematic review and meta-analysis were performed to determine the relationship between SDF-1/ CXCL12 3'A-gene polymorphism and risk of CAD from 5 years of current studies.

\section{Methods}

\section{Literature eligibility criteria}

Eligibility criteria were created based on the PICO framework. PICO criteria used in this study as follows: (1) Patient: Adult people; (2) Interest: CAD; (3) Control: non-CAD; and (4) Outcome: The polymorphism of SDF-1/CXCL12 AA-genes. The articles used in this study included all literature that provided full-text articles regarding the comparison of SDF-1/CXCL12 3'A-gene polymorphism and non-polymorphism in CAD patients. We exclude review, animal, anatomic, cadaveric, qualitative, and economic studies. Articles made by the same author in the same institution were performed sample evaluation to prevent sample duplication. We included studies published in Bahasa and English. Other languages were translated using google translate and decided by the author whether they include them or not. Five-year studies (2013-2018) were included to provide the current results.

This review included studies with adult participants (age 18 years or older) of both genders who have suffered CAD. CAD was defined as is the narrowing or blockage of the coronary arteries, usually caused by atherosclerosis. There are different terms used regarding $\mathrm{CAD}$ in this study, such as $\mathrm{MI}$ and coronary heart disease (CHD). The reviewed interest was SDF-1 3'A-gene polymorphism. SDF-1 3'A-gene polymorphism is defined as a presence of SNP (rs1065297, rs1801157, rs266089, rs197452, rs2839693, and/or rs10793538) in HHEX gene located on chromosome 10q24 participants of all nationalities, ethnic, and race were included in this study.

\section{Methods for identifying evidence}

We extracted the eligibility criteria (PICO) into keywords using Boolean operator. In this study, we used keywords ((stromal cell-derived factor-1) odds ratio (OR) stromal cell-derived factor 1) OR SDF-1) OR SDF1) OR CXCL 12) OR CXCL-12) OR CXCL12) AND (coronary artery disease) OR CAD) OR CHD) OR CHD) AND (polymorphism) OR gene mutations)) in PubMed, EBSCO, Google Scholar, and Directory of Open Access Journal (DOAJ) database to find the eligible studies.

The study selection process was performed by two independent authors (IPYP and EM) to reduce the possibility of discarding relevant studies. The decision of another author was used when a disagreement occurred. Duplicate records were removed. Titles and abstracts were screened and irrelevant studies were removed. Studies that passed the first screening were further evaluated for the compliance of the inclusion and exclusion criteria of this review. Finally, the studies were further evaluated for their quality before included in this review.

\section{Study selection}

In the first phase, the title of the literature was examined and irrelevant studies such as review articles, non-experimental studies, as well as anonymous authors, were removed. In the next phase, the fulltext of potentially relevant literature was retrieved and examined for compliance with the eligibility criteria of this review; the selected literature must meet the inclusion and exclusion criteria such as case-control study, including OR, as well as full-text articles. Finally, the selected literature was assessed for their evidence before being included in the final review (Figure 1).

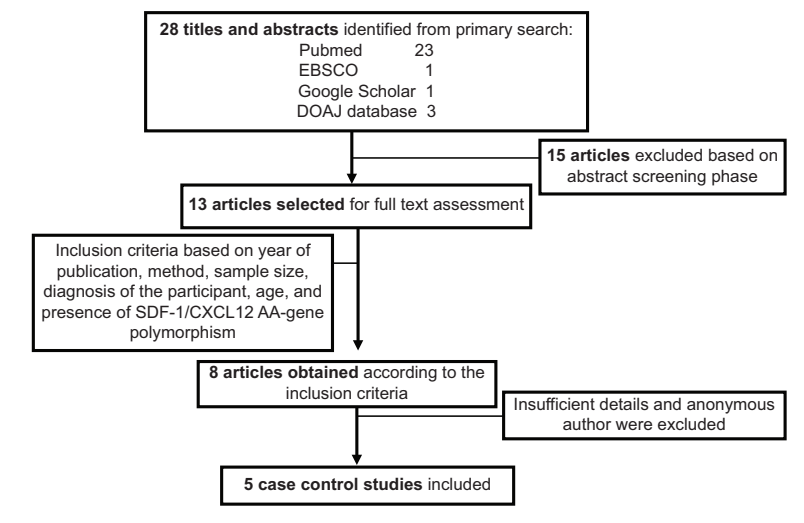

Figure 1: The PRISMA diagram of literature selection in this study

\section{Data collection}

Literature that was identified merged and managed for further analysis. All of the selected literature 
was thoroughly read and apprehended to extract the principle of the literature. An electronic data collection form was used to collect data from each author. The collected data by each author will be merged and be managed with software Review Manager 5.3. The data items were the author's name, year of publication, method, sample size, diagnosis of the participant, age, and presence of SDF-1/CXCL12 AA-gene polymorphism. They were calculated for the OR and were analyzed.

\section{Quality study assessment}

Studies that complied with inclusion and exclusion criteria were assessed for their quality to ensure the validity and reliability of the studies. This process was done independently by two authors using a standardize critical appraisal tool to minimize the possibility of bias in the study selection. The critical appraisal tool in this study was the Joanna Briggs Institute (JBI) critical appraisal tool based on study design. A decision of the third and fourth authors was used when a disagreement occurred.

The cutoff point was used to determine the quality of the study. The cutoff point in this review was half of the total score in each JBI critical appraisal checklist. The lowquality study was defined as a score below the cutoff point while conversely was termed as a high-quality study.

\section{Synthesis of results}

All relevant literature regarding SDF-1/CXCL12 3'A-gene polymorphism and risk of CAD were included in the narrative synthesis. The OR of outcome was pooled and analyzed. Meta-analyses were performed using software Review Manager 5.3. Fixed effect model was used because the included studies were homogenous. The narrative synthesis was conducted systematically to gain a different perspective based on the previous current studies (2013-2018).

\section{Results}

The study results yielded five studies to be analyzed (Table 1) which can be included in the study [14], [15], [16], [17], [18]. All five articles were observational case-control studies. We did not find any randomized clinical trial study comparing SDF1 AA-gene polymorphism in CAD patients and control. All five articles were considered as a good quality based on our judgment. The article searching process was carried out based on the PRISMA principle (Figure 1).

According to Table 1, all of the studies are using polymerase chain reaction technique to determine the polymorphism of the SDF-1 gene. A total of 1819 cases and 2030 control were included from five different studies during the 2013-2018 period. Based on those studies, there were 155 SNP of AA gene among CAD patients, compared with 104 SNP of AA gene in nonCAD patients. The OR analysis for risk assessment was ranging from 1.10 to 7.37 among studies. However, to evaluate the overall effect regarding those studies, the meta-analysis using forest-plot was conducted (Figure 2).

Table 1: The summary of studies in this meta-analysis for the main comparison among variables

\begin{tabular}{|c|c|c|c|c|c|c|c|c|}
\hline Study author & Type of study & Methods & Subject condition & Case & $\mathrm{n}$ & Control & $\mathrm{n}$ & Outcome \\
\hline Mansoori et al., 2017 & $\begin{array}{l}\text { Observational study, } \\
\text { case-control }\end{array}$ & PCR & $\begin{array}{l}\text { One-hundred-twenty Iranian adult patients with } \\
\text { myocardial infarction and } 120 \text { healthy individual }\end{array}$ & $\mathrm{MI} / \mathrm{CAD}$ & 120 & No MI/CAD & 120 & $\begin{array}{l}\text { CAD: } 7 \text { SDF1 AA gene, No } \\
\text { CAD: } 1 \text { SDF1 AA gene }\end{array}$ \\
\hline Borghini et al., 2014 & $\begin{array}{l}\text { Observational study, } \\
\text { case-control }\end{array}$ & PCR & $\begin{array}{l}\text { Two-hundred of myocardial infarction patients and } \\
230 \text { healthy individuals }\end{array}$ & $\mathrm{MI} / \mathrm{CAD}$ & 200 & No MI/CAD & 230 & $\begin{array}{l}\text { CAD: } 12 \text { SDF1 AA gene, No } \\
\text { CAD: } 21 \text { SDF1 AA gene }\end{array}$ \\
\hline Gu et al., 2013 & $\begin{array}{l}\text { Observational study, } \\
\text { case-control }\end{array}$ & PCR & $\begin{array}{l}\text { Five-hundred-ninety-two patients with CAD and } 625 \\
\text { healthy individuals }\end{array}$ & CAD & 592 & No CAD & 625 & $\begin{array}{l}\text { CAD: } 101 \text { SDF1 AA gene, No } \\
\text { CAD: } 54 \text { SDF1 AA gene }\end{array}$ \\
\hline Eba et al., 2018 & $\begin{array}{l}\text { Observational study, } \\
\text { case-control }\end{array}$ & PCR & $\begin{array}{l}\text { Three-hundreds-ten chromosomes of CAD patients } \\
\text { and } 370 \text { chromosomes of healthy individuals }\end{array}$ & CAD & 310 & No CAD & 370 & $\begin{array}{l}\text { CAD: } 14 \text { SDF1 AA gene, No } \\
\text { CAD: } 6 \text { SDF1 AA gene }\end{array}$ \\
\hline Zhang et al., 2017 & $\begin{array}{l}\text { Observational study, } \\
\text { case-control }\end{array}$ & PCR & $\begin{array}{l}\text { Five-hundred-ninety-seven patients with diagnosis of } \\
\text { CHD patients and } 685 \text { healthy individual }\end{array}$ & CAD & 597 & No CAD & 685 & $\begin{array}{l}\text { CAD: } 21 \text { SDF1 AA gene, No } \\
\text { CAD: } 22 \text { SDF1 AA gene }\end{array}$ \\
\hline
\end{tabular}
PCR: Polymerase chain reaction, CAD: Coronary artery disease, MI: Myocardial infarction, SDF1: Stromal cell-derived factor-1.

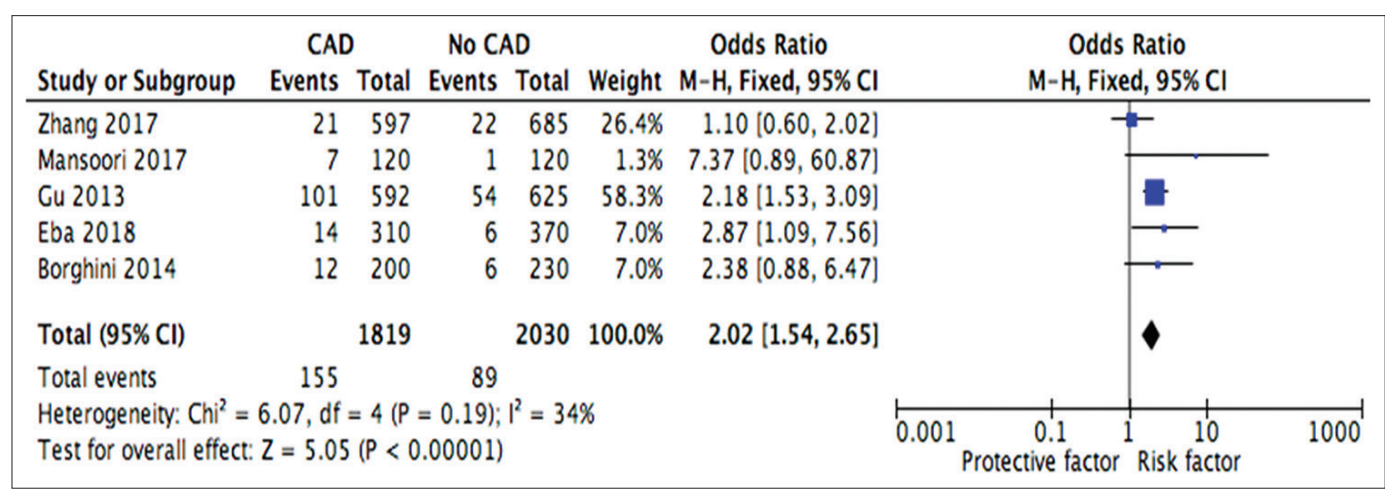

Figure 2: Forest plot regarding single-nucleotide polymorphism in stromal cell-derived factor-1/chemokine (C-X-C motif) ligand 12 gene 
The forest plot in Figure 2 showed that the fixed effect model analysis was used due to the p-value $>0.05$ in the heterogeneity test $\left(I^{2}=34 \% ; X^{2}=6.07 ; p=0.19\right)$. The test for overall effect was assessed based on pooled OR, whereas finding statistically significant about 2.02 times higher risk for CAD compared with patients without SNP in SDF-1 gene ( $p<0.00001 ; 95 \%$ confidence interval: 1.54-2.65) (Figure 2).

To exclude the risk of publication bias, funnel plot assessment was conducted (Figure 3). According to the funnel plot, it can be assumed that all results of five different studies are symmetrical and this indicates the results of the study having a low publication bias (Figure 3).

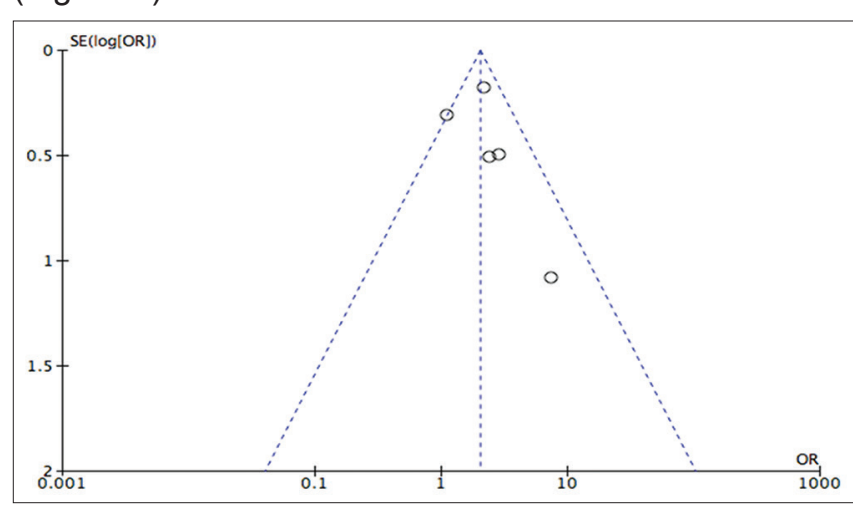

Figure 3: Funnel plot assessment among five different studies regarding single-nucleotide polymorphism in the stromal cell-derived factor-1 gene

\section{Discussion}

Our meta-analysis from 5 eligible studies indicated a significant association between the 3'A-gene polymorphism in SDF-1 and risk of CAD. However, several pieces of evidence regarding those associations were inconclusive based on risk analysis. According to results, we can assume that genetic polymorphism will change the level expression of SDF-1 in the bloodstream. Genetic phenotyping analysis studies recently have addressed the association between the variation of $10 q 11.21$ locus harboring SDF-1 gene, also known as CXCL-12, and CAD. SDF-1 belongs to a chemoattractant family and responsible for SPCs and endothelial progenitor cells (EPCs) and implicated in atherosclerosis plaque formation. SDF-1 also has a role in neutrophil and lymphocyte recruitment to atherosclerosis lesion and affects plaque stabilization. The SDF-1 3'A polymorphism (rs1065297, rs1801157, rs266089, rs197452, rs2839693, and/or rs10793538) in HHEX gene is a newly identified SNP which involves guanine (G) to adenosine $(A)$ transition at UTR of SDF-1 gene. This mutation regulates change in SDF-1 expression and been linked to CAD susceptibility [10], [19], [20].
In contrast to $G$ allele, mutation at $A$ allele is found to correlate with SDF-1 overexpression. The effect of high SDF-1 production, however, remains controversial and the results vary across ethnic groups. There were only a few studies about SDF-1 3'A polymorphism existed, and some demonstrated a protective role of high SDF-1 expression in AA genotype groups on CAD risk [21]. Conversely, studies by Mansoori et al. and $\mathrm{Gu}$ et al. demonstrated completely different findings in which SDF-1 3'A polymorphism related SDF-1 upregulation expressed significantly higher in the CAD group than in the non-CAD group [15], [16]. Based on those findings, we conducted a meta-analysis to further elaborate and analyze this diversity in study findings.

We performed meta-analysis from the five newest different studies analyzing SDF-1 3'A gene polymorphism in diverse ethnic background, Iranian, Chinese, Indian, and Italian population. The pooled OR from these five case-control studies suggested that the presence of SDF-1 3'A gene polymorphism as a genetic risk factor for CAD [14], [15], [16], [17], [18]. The present finding was in contrast to a former meta-analysis by $\mathrm{Wu}$ et al. which elaborated association between rs1801157/SDF-1 gene polymorphism and CHD [19]. In this aforementioned study, they did not specifically analyze the AA phenotype, instead they did five genetic subgroup analysis of $A A, G G, A G$ versus $G G, A A / A G$ versus $G G$, and $A A$ versus $A G / G G$ phenotypes, and eventually jump into the conclusion that rs1801157/ SDF-1 gene polymorphism was not increased susceptibility to CHD and may serve as protective factor for MI. However, a meta-analysis by Wu et al. possessed strong heterogeneity across studies due to a difference in CHD subtype defines across studies and the number of respondents recruited [19]. This metaanalysis showed a current study from 5 years period (2013 to 2018) and also resulted in low publication bias based on the funnel plot.

The present study exclusively focused on the AA phenotype polymorphism, which was yet explored in other studies and may serve as a good foundation to a more solid and reliable meta-analysis in the near future. Nevertheless, there were still some issues that could be attributed to the limitation of the current study. First, the lack of available studies on this related field caused inevitably a small sample size of only 1819 total CAD cases. Another limitation was related to heterogeneity in the case of selection due to there were only five eligible studies during 2013-2018. Although all studies defined CAD cases based on coronary angiography findings, in three studies patients was diagnosed with $\mathrm{Ml}$ and later confirmed by the invasive study to have CAD, whereas in studies by Eba et al. and Zhang et al., there was no clear explanation about the occurrent of $\mathrm{MI}$ in CAD groups [14], [18]. At the end, all those subjects shared a common underlying pathogenic process, atherosclerosis, and the SDF-1 gene polymorphism, therefore strongly correlated with CAD [14], [15], [16], [18]. 
SDF- 1 is a chemokine that regulating neutrophil migration to the atherosclerosis lesion [22], [23]. Damås et al. yielded a result that increased in SDF-1 level associated with anti-inflammatory and matrixstabilizing effects in MI [22]. This effect might be a result from potent chemoattractant properties of SDF-1 in recruiting EPC through binding with CXCR4 and CXCR7 receptors [23]. However, a higher plasma SDF-1 level was associated in reduced frequency of $\mathrm{CD}_{3} 4^{+}$cell phenotypes, a circulating cell marker associated with progenitor cell activity [24]. Previous studies have found that SDF-1 binds to the CXCR4 receptor found on $\mathrm{CD} 34^{+}$cells and triggers CD34+ cell release from the bone marrow [25]. The CD $34^{+}$cell itself is responsible for angiogenesis and neovascularization to mediate ischemic healing after CAD [26]. Based on those results, we can assume that SDF-1 3'A-gene polymorphism associated with its overexpression, whereas inversely reduced the $\mathrm{CD} 34^{+}$cell phenotype as one of the protective factors against CAD. Even this meta-analysis showed a statistically significant association between SDF-1 3'A gene polymorphism and risk of CAD, lack number of participants included during 5 years study was a study limitation compared with the previous studies.

\section{Authors' Contributions}

IPYP, AAWL, and IMM are responsible for the conceptual framework, data analysis, and interpreting the results. GARP, IMJRA, IKR, and PEM are responsible for statistical analysis in this study. In addition, AB, SHR, and IBAPM are responsible for criticizing the results as well as English improvement.

\section{References}

1. GBD 2013 Mortality and Causes of Death Collaborators. Global, regional, and national age-sex specific all-cause and cause-specific mortality for 240 causes of death, 1990-2013: A systematic analysis for the global burden of disease study 2013. Lancet. 2015;385(9963):117-71. https://doi.org/10.1016/ s0140-6736(14)61682-2

PMid:25530442

2. Álvarez-Álvarez MM, Zanetti $\mathrm{D}$, Carreras-Torres $\mathrm{R}$, Moral $\mathrm{P}$, Athanasiadis G. A survey of Sub-3.Saharan gene flow into the Mediterranean at risk loci for coronary artery disease. Eur J Hum Genet. 2017;25(4):472-6. https://doi.org/10.1038/ejhg.2016.200 PMid:28098150

3. Ross R, Glomset J, Harker L. Response to injury and atherogenesis. Am J Pathol. 1977;86(3):675-84. PMid:842616

4. Tedgui A, Mallat Z. Cytokines in atherosclerosis: Pathogenic and regulatory pathways. Physiol Rev. 2006;86(2):515-81. https://doi. org/10.1152/physrev.00024.2005

PMid: 16601268

5. Alam SE, Nasser SS, Fernainy KE, Habib AA, Badr KF. Cytokine imbalance in acute coronary syndrome. Curr Opin Pharmacol. 2004:4(2):166-70.

PMid:15063361

6. Farouk SS, Rader DJ, Reilly MP, Mehta NN. CXCL12: A new player in coronary disease identified through human genetics. Trends Cardiovasc Med. 2010;20(6):204-9. https://doi. org/10.1016/j.tcm.2011.08.002

PMid:22137643

7. Akhtar S, Gremse F, Kiessling F, Weber C, Schober A. CXCL12 promotes the stabilization of atherosclerotic lesions mediated by smooth muscle progenitor cells in apoe-deficient mice. Arterioscler Thromb Vasc Biol. 2013;33(4):679-86 https://doi. org/10.1161/atvbaha.112.301162

PMid:23393393

8. Teicher BA, Fricker SP. CXCL12 (SDF-1)/CXCR4 pathway in cancer. Clin Cancer Res. 2010;16(11):2927-31. https://doi. org/10.1158/1078-0432.ccr-09-2329

PMid:20484021

9. Melamed KH, Goldhaber SZ. Cardiology patient page: Inflammation and myocardial infarction. Circulation. 2014;130(24):e334-6.

PMid:25602951

10. Subramanian S, Liu C, Aviv A, Ho JE, Courchesne P, Muntendam P, et al. Stromal cell-derived factor 1 as a biomarker of heart failure and mortality risk. Arterioscler Thromb Vasc Biol. 2014;34(9):2100-5. https://doi.org/10.1161/atvbaha.114.303579 PMid:25060794

11. Feng L, Nian SY, Hao YL, Xu WB, Zhang XF, Li D, et al. A single nucleotide polymorphism in the stromal cellderived factor 1 gene is associated with coronary heart disease in Chinese patients. Int J Mol Sci. 2014;15(6):11054-63. https://doi.org/10.3390/ ijms150611054

PMid:24950177

12. Samani NJ, Erdmann J, Hall AS, Hengstenberg C, Mangino M, Mayer B. Genomewide association analysis of coronary artery disease. New Engl J Med. 2007;357(5):443-53.

PMid: 17634449

13. Szalai C, Duba J, Prohászka Z, Kalina A, Szabó T, Nagy B, et al Involvement of polymorphisms in the chemokine system in the susceptibility for coronary artery disease (CAD). Coincidence of elevated $L p(a)$ and MCP-1-2518 G/G genotype in CAD patients. Atherosclerosis. 2001;158(1):233-9. https://doi.org/10.1016/ s0021-9150(01)00423-3

PMid:11500196

14. Eba A, Raza ST, Abbas M, Rizvi S, Rajput M, Mahdi F. Association of SDF1 $\beta$ (G801A) and GNB3 (C825T) polymorphisms with the incidence and severity of coronary artery disease. $\mathrm{Br} \mathrm{J}$ Biomed Sci. 2019;76(1):49-51. https://doi.org/10.1080/09674845.2018. 1527802

PMid:30253706

15. Mansoori Y, Daraei A, Zendebad Z, Madadizadeh F, Mansoori B, Naghizadeh MM, et al. The SDF1 A/G gene variant: A susceptibility variant for myocardial infarction. Genet Test Mol Biomarkers. 2017;21(8):506-11. https://doi.org/10.1089/ gtmb.2017.0023 PMid:28650670

16. Gu XL, Ma N, Xiang DC, Huang J, Dong ZH, Lei HY, et al. Polymorphism of stromal cell-derived factor 1 selectively upregulates gene expression and is associated with increased susceptibility to coronary artery disease. Biochem Biophys Res Commun. 2014;443(3):932-7. https://doi.org/10.1016/j. bbrc.2013.12.065 
PMid:24361877

17. Borghini A, Sbrana S, Vecoli C, Mercuri A, Turchi S, Carpeggiani C, et al. Stromal cell-derived factor-1-3'A polymorphism is associated with decreased risk of myocardial infarction and early endothelial disturbance. J Cardiovasc Med (Hagerstown). 2014;15(9):710-6. https://doi.org/10.2459/ jcm.0000000000000068

PMid:24751515

18. Zhang J, Ma H, Gao J, Kong S, You J, Sheng Y. Variants in the CXCL12 gene was associated with coronary artery disease susceptibility in Chinese Han population. Oncotarget. 2017;8(33):54518-27. https://doi.org/10.18632/ oncotarget. 17171

PMid:28903360

19. Wu N, Zhang $X$, Jia $P$, Jia D. Lack of an association between the SDF-1 rs1801157 polymorphism and coronary heart disease: A meta-analysis. Sci Rep. 2015;5:11803. https://doi.org/10.1038/ srep11803

20. van der Vorst EP, Doring Y, Weber C. MIF and CXCL12 in cardiovascular diseases: Functional differences and similarities. Front Immunol. 2015;6:373. https://doi.org/10.3389/ fimmu.2015.00373

PMid:26257740

21. Luan B, Han Y, Zhang X, Kang J, Yan C. Association of the SDF13'A polymorphism with susceptibility to myocardial infarction in Chinese Han population. Mol Biol Rep. 2010;37(1):399-403. https://doi.org/10.1007/s11033-009-9845-3

PMid:19821058

22. Damås JK, Waehre $\mathrm{T}$, Yndestad A, Ueland T, Müller F,
Eiken HG, et al. Stromal cell-derived factor-1alpha in unstable angina: Potential antiinflammatory and matrix-stabilizing effects. Circulation. 2002;106(1):36-42. https://doi.org/10.1161/01 cir.0000020001.09990.90

PMid: 12093767

23. Rath $D$, Chatterjee M, Borst $O$, Müller $K$, Stellos $K$, Mack AF, et al. Expression of stromal cell-derived factor-1 receptors CXCR4 and CXCR7 on circulating platelets of patients with acute coronary syndrome and association with left ventricular functional recovery. Eur Heart J. 2014;35:386-94. https://doi. org/10.1093/eurheartj/eht448

PMid:24168792

24. Xiao $Q$, Ye $S$, Oberhollenzer F, Mayr A, Jahangiri M, Willeit J, et al. SDF1 gene variation is associated with circulating SDF1alpha level and endothelial progenitor cell number: The Bruneck study. PLoS One. 2008;3(12):e4061. https://doi. org/10.1371/journal.pone.0004061 PMid: 19115008

25. Aiuti A, Webb IJ, Bleul C, Springer T, Gutierrez-Ramos JC. The chemokine SDF-1 is a chemoattractant for human CD34+ hematopoietic progenitor cells and provides a new mechanism to explain the mobilization of CD34+ progenitors to peripheral blood. J Exp Med. 1997;185:111-20. https://doi.org/10.1084/ jem.185.1.111 PMid:8996247

26. Asahara $T$, Murohara $T$, Sullivan A, Silver M, van der Zee $R$, $\mathrm{Li} \mathrm{T}$, et al. Isolation of putative progenitor endothelial cells for angiogenesis. Science. 1997;275:964-7. https://doi.org/10.1126/ science. 275.5302 .964

PMid:9020076 